\title{
ORDENAMENTO DA VISITAÇÃO PÚBLICA DA PRAIA DO ITACURUÇÁ/PEREIRINHA, PARQUE ESTADUAL DA ILHA DO CARDOSO, CANANÉIA-SP
}

\author{
Marcos Buhrer Campolim ${ }^{1}$ \\ Edison Rodrigues do Nascimento ${ }^{2}$ \\ Juliano Silva do Nascimento ${ }^{2}$
}

\begin{abstract}
RESUMO
O estudo descreve o processo de elaboração da proposta de ordenamento emergencial da visitação pública na praia do Itacuruçá/Pereirinha, Parque Estadual da Ilha do Cardoso, Cananéia, São Paulo, Brasil. Foi utilizado metodologia de planejamento participativo com os atores que atuam no setor de turismo náutico e receptivo de praia para a formatação da proposta. A presença de populações de boto cinza (Sotalia guianensis) molestadas pelo tráfego de embarcações e o excesso de visitantes em dias de pico na praia foram os principais motivos para o desenvolvimento do trabalho o qual resultou em norma formalizada e em planos de ações.
\end{abstract}

Palavras chave: Boto Cinza Sotalia guianensis; Turismo náutico; Unidade de Conservação

\begin{abstract}
This study describes the creation process of the emergency planning proposal for public visiting to Itacuruça/Pereirinha Beach, Ilha do Cardoso, Cananéia, São Paulo, Brazil. A participative planning method was used to generate the proposal with actors who operate in the nautical and receptive tourism on the beach. Estuarine dolphins (Sotalia guianensis) molested by boat traffic and the excess of visitors at the beach in peak days were the main reason for developing this work which resulted in formalized rule and action plans.
\end{abstract}

Keywords: Guiana dolfhins Sotalia guianensis; Nautical tourism, Protected Areas

\section{INTRODUÇÃO}

O Parque Estadual da Ilha do Cardoso (PEIC) foi criado pelo Decreto Estadual $\mathrm{n}^{\circ}$ 40.319/62 em 03 de julho de 1962, está localizado no município de Cananéia, no extremo sul do estado de São Paulo e conta com área de 13.600 hectares (SÃO PAULO, 2011). Trata-se de uma Unidade de Conservação (UC) da categoria de proteção integral que tem como objetivos a preservação de ecossistemas naturais, pesquisas científicas, educação e interpretação ambiental, recreação e turismo ecológico (BRASIL, 2001). A Fundação

\footnotetext{
${ }^{1}$ Divisão de Parques e Reservas Estaduais - Instituto Florestal - Secretaria do Meio Ambiente do Estado de São Paulo. E-mail: marcoscampolim@yahoo.com.br

${ }^{2}$ Parque Estadual da Ilha do Cardoso - Fundação Florestal - Secretaria do Meio Ambiente do Estado de São Paulo. E-mail: pe.ilhacardoso@fflorestal.sp.gov.br
} 
Florestal, vinculada à Secretaria do Meio Ambiente do Estado de São Paulo, é responsável pela administração do PEIC.

O Parque integra a maior área contínua de floresta atlântica do Brasil e está inserido no complexo estuarino-lagunar de Iguape, Cananéia e Paranaguá, região reconhecida como Sítio do Patrimônio Mundial Natural (UNESCO, 1999) e Zona Núcleo da Reserva da Biosfera (UNESCO, 2005). Várias categorias de UCs próximas ao PEIC integram os mosaicos de unidades de conservação do Jacupiranga (UCs estaduais) e do Litoral Sul e Litoral do Paraná (UCs federais, estaduais, municipais e particulares). Vários ambientes estão presentes na região tais como costões rochosos, praias, braços de mar, estuários, barras, lagunas, restingas, manguezais, rios, planície litorânea, ilhas e montanhas cobertas por florestas. Constitui um complexo conjunto de ecossistemas, onde já foram catalogadas quase mil espécies de plantas e onde se encontram muitos animais ameaçados de extinção, como o papagaio-de-cara-roxa e jacaré-de-papo-amarelo (SÃO PAULO, 2001). No Parque estão presentes comunidades tradicionais caiçaras reconhecidas pelo seu Plano de Manejo as quais desenvolvem atividades pesqueiras e de turismo de base comunitária (SÃO PAULO, 2001).

A visitação pública em parques deve ser priorizada dentro dos critérios estabelecidos pelo Sistema Nacional de Unidades de Conservação - SNUC e Regulamento de Parques Estaduais Paulistas e desenvolvida com a participação da comunidade local, sensibilizando o visitante sobre a importância da conservação para as atuais e futuras gerações. A implantação das atividades de ecoturismo deve ser planejada criteriosamente e com monitoramento dos impactos para evitar a destruição dos atributos naturais que justificaram a criação da UC.

O Programa de Manejo "Visitação Pública e Educação Ambiental" do Plano de Manejo do Parque Estadual da Ilha do Cardoso frisa que as atividades de visitação pública devem ser compatibilizadas com a fragilidade dos ambientes do parque (zoneamento, recursos humanos, infra-estrutura e características dos atrativos) e regulamentadas em cada área/atrativo, com a definição de normas e procedimentos voltados para o público que visita a Unidade de Conservação (SÃO PAULO, 2011).

Localizada na parte norte do Parque Estadual da Ilha do Cardoso, a Praia do Itacuruçá, também conhecida como Praia do Pereirinha, ocorre um fenômeno raro, a presença diária do boto cinza (Sotalia guianensis), espécie com hábito preferencial por águas estuarinas, com população estimada em 300 indivíduos para esta região (SANTOS, 2010). A topografia desta praia propicia aos botos as condições adequadas para captura de peixes que por ali se protegem de predadores (SANTOS, 2010).

Vários estudos sobre o boto-cinza na região de Cananéia tiveram foco sobre aspectos comportamentais e ecológicos (GEISE, 1989; MONTEIRO FILHO, 1991; MONTEIROFILHO, 2000; FILLA, 2004; SANTOS, 2004; SANTOS E ROSSO, 2007; FILLA, 2008; SANTOS, 2010; GODOY et al., 2015) e de interação com atividades de turismo e ordenamento de visitação (FILLA, 2008; FILLA e MONTEIRO-FILHO, 2008; FILLA e MONTEIRO-FILHO, 2009_A e 2009_B; SANTOS et al., 2010; FILLA et al., 2012).

A avistagem de botos se tornou atração turística, podendo ser facilmente observado tanto a bordo de embarcações quanto a partir de alguns pontos em terra (FILLA, 2009). Estudos na região indicam potenciais danos sob o ponto de vista da conservação do boto- 
cinza decorrentes da aproximação exagerada de embarcações (FILLA, 2008; SANTOS, 2010) ocasionando molestamento e eventualmente machucando os animais (Figura 1) e de problemas ocasionados pelo som produzido pelos motores (REZENDE, 2008).

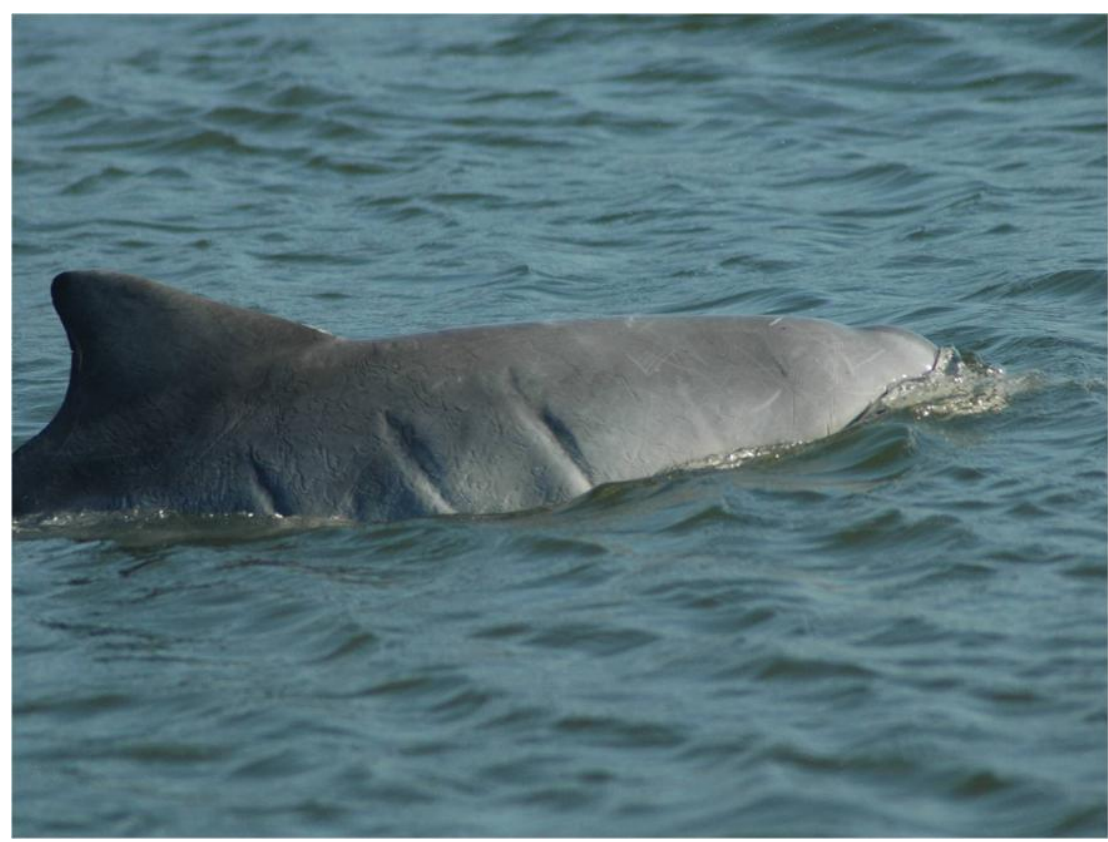

Figura 1 - Boto cinza com cicatrizes ocasionadas por hélice de embarcações (SANTOS, 2010).

O turismo náutico na região de Cananéia iniciou na década de 70 com foco direcionado para transportar pescadores esportivos e posteriormente por pessoas que vinham para a região atraídas pelo seu patrimônio natural, histórico e cultural, contribuindo desta forma para instalação de infra-estruturas nas comunidades para receber o turista (FILLA, 2009). Devido ao aumento da demanda turística por passeios náutico principalmente na praia do Itacuruçá/Pereirinha, de 2009 a 2015 houve uma grande readequação nas embarcações do tipo "voadeiras" que atuam com turismo náutico, passando de motores de $25 \mathrm{hp}$ de potência e capacidade de 4 passageiros para embarcações acima de $90 \mathrm{hp}$ com capacidade de mais de 10 passageiros. Esta nova frota náutica passou de 2 para 5 a 6 viagens diárias, quando em feriados e períodos de finais de semana de verão. As escunas, embarcações que transportam entre 40 a 120 passageiros e que desenvolvem velocidades de deslocamento menores que as voadeiras, mantiveram as características neste mesmo período.

Estudos realizados na região evidenciaram a ausência e a necessidade de ações voltadas para o ordenamento do turismo de observação de botos (FILLA, 2008; SANTOS, 2010).

Com base nos estudos comportamentais do boto-cinza e de sua interação com atividades de turismo, no ano de 2007 a Fundação Florestal publicou a Portaria Normativa FF/DE n $^{\circ}$ 045/2007 que estabeleceu normas e procedimentos para o credenciamento de embarcações de turismo comercial e a limitação da navegação às embarcações que navegam no entorno do PEIC, a fim de preservar as populações de boto-cinza, ordenar a visitação pública e prevenir contra a poluição do meio ambiente marinho. Esta portaria delimitou uma área restrita na Praia do Itacuruçá/Pereirinha onde não é permitido o trânsito de embarcações, o desembarque em praia ou costão rochoso e a atividade de pesca. Nesta área restrita, somente os moradores 
tradicionais locais podem realizar o fundeio de embarcações e o desembarque e embarque em atividade exclusiva de transporte de provisões e de pescados e a pesca de subsistência.

No ano de 2011, a Prefeitura Municipal da Estância de Cananéia, publicou a Lei Municipal $\mathrm{n}^{\circ}$ 2.129/2011, que Regulamenta as atividades com fins comerciais de Turismo, Lazer e Esporte Náutico no Município de Cananéia. Esta Lei estabelece a quantidade de embarcações que podem operar com turismo náutico e proíbe esportes náuticos potenciais causadores de molestamento aos cetáceos (Jet sky, esqui aquático, entre outros) nas áreas de maior ocorrência de cetáceos, como a Praia do Itacuruçá/Pereirinha.

No ano de 2013, o parque registrou um aumento considerável do número de visitantes na Praia do Itacuruçá/Pereirinha, chegando a 41.350 pessoas, dobrando o número de visitantes em relação ao ano anterior (Figura 2). Ressalta-se que os dados de visitação evidenciaram outro problema, o aumento no número de pessoas por dia que visitam a referida praia, chegando a picos de 2.500 pessoas em um único dia. Na temporada 2014/2015 o número de pessoas chegou a mais de 4.000 pessoas em um único dia (estatística de visitantes PEIC - não publicado).

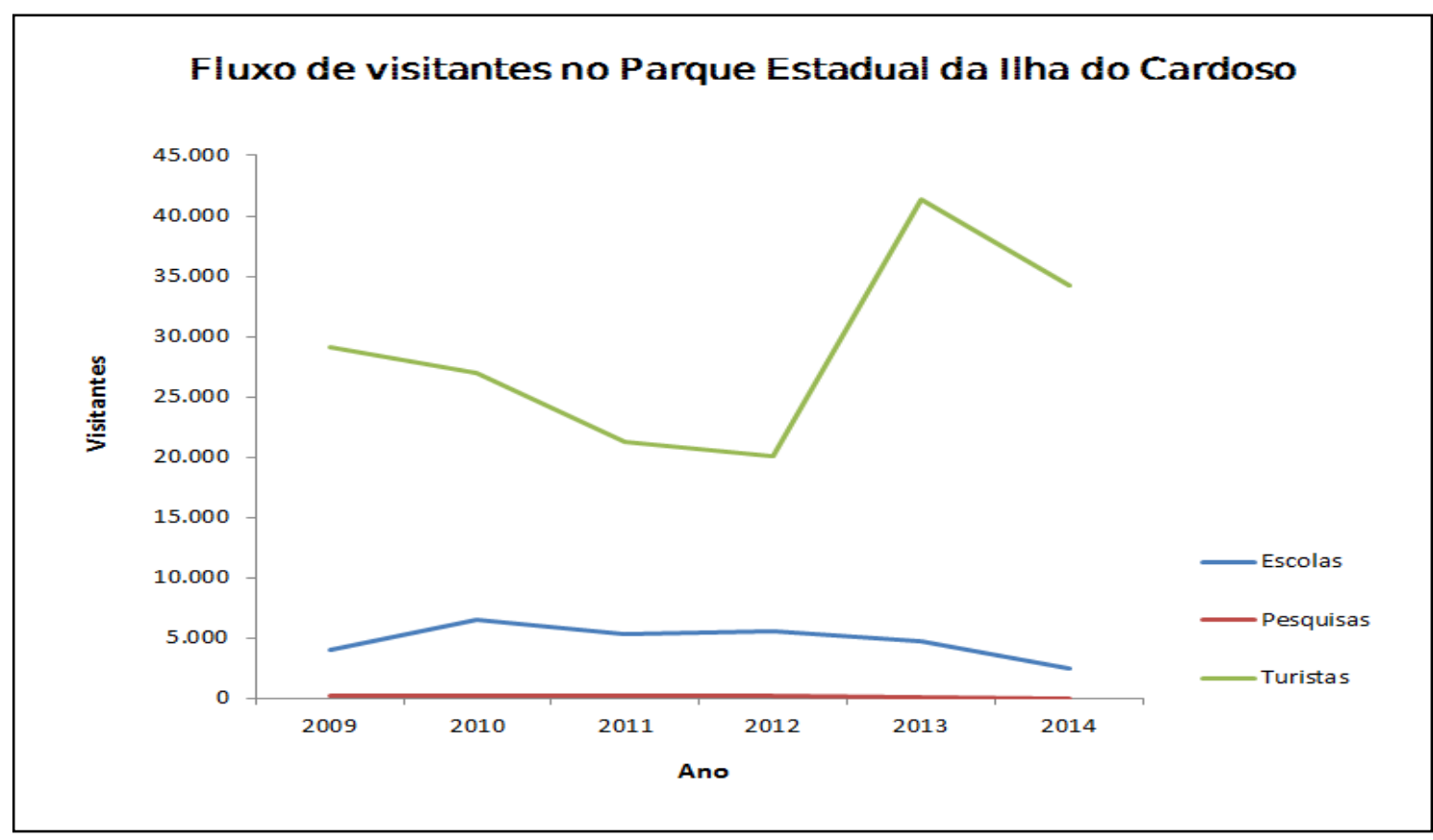

Figura 2 - Dados de visitação coletados entre os anos de 2009 e 2014 (arquivo PEIC).

Este aumento significativo no número de visitantes na Praia do Itacuruça/Pereirinha, registrado nos últimos anos, principalmente durante os feriados prolongados e no período correspondente ao verão é incompatível com os objetivos da Unidade de Conservação, pois vem ocasionando diversos impactos ambientais à mesma e devido à grande circulação de embarcações constitui ameaça a população de boto-cinza presentes na região.

Diante deste cenário, o Conselho Consultivo do Parque Estadual da Ilha do Cardoso decidiu em sua $176^{a}$ reunião a necessidade de elaboração urgente de regramento para a referida praia, para minimização dos impactos resultantes da visitação pública.

Este artigo tem como objetivo descrever o processo de elaboração da proposta de limitação emergencial da visitação pública na praia do Itacuruçá/Pereirinha utilizando 
metodologia participativa com os atores que atuam no setor de turismo náutico e receptivo de praia.

\section{MATERIAL E MÉTODOS}

A praia do Itacuruçá/Pereirinha está localizada no extremo norte do Parque Estadual da Ilha do Cardoso (Figura 3), município de Cananéia, litoral sul de São Paulo. Esta praia compreende a comunidade tradicional do Itacuruçá e está próxima do Núcleo Pereque, sede de visitação pública do PEIC na Ilha.

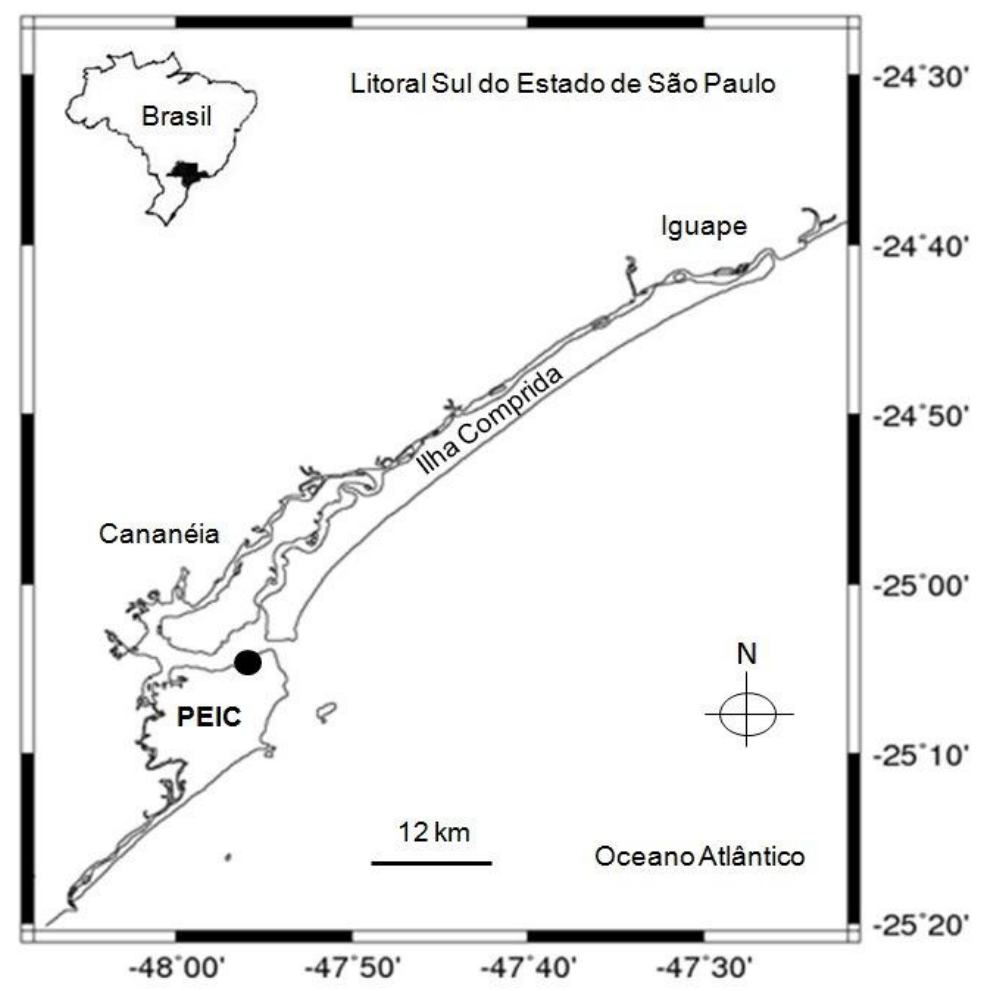

Figura 3 - Localização praia do Itacuruçá/Pereirinha - PEIC (Moaes \& Mignon, 2012).

De modo a atender conceitos de turismo sustentável e de base comunitária e utilizar ferramentas de planejamento e gestão participativa utilizou-se metodologia de processo comunitário de ordenamento de visitação pública (MITRAUD, 2004; MEDINA, 2005, CAMPOLIM et al., 2008; CAMPOLIM et al., 2013) com os segmentos envolvidos na atividade de turismo, que incluem os moradores da comunidade tradicional do Itacuruçá/Pereirinha os quais realizam o receptivo turístico na praia, os prestadores de serviço de transporte náutico (escunas e voadeiras), os funcionários da Fundação Florestal que atuam no controle da visitação e o setor responsável pelas atividades de turismo da Prefeitura Municipal da Estância de Cananéia.

A participação social em metodologias de análise do manejo de áreas protegidas baseiase em entender os problemas atuais do local e orientá-los a atingir o objetivo de conservação. A legitimidade social ocorre quando os atores reconhecem, apropriam e incorporam no desenvolvimento de suas vidas os objetivos de conservação, a existência da área protegida e a função pública de conservação exercida pelas autoridades competentes (MEDINA, 2005). 
A partir da indicação do Conselho Consultivo do Parque Estadual da Ilha do Cardoso para a elaboração de regramento para a praia do Itacuruçá/Pereirinha foi criado um Grupo de Trabalho (GT) dentro da Câmara Temática (CT) de Uso Público deste Conselho para elaboração de proposta.

O Grupo de Trabalho definiu como base para elaboração do ordenamento emergencial da referida praia, os princípios e diretrizes contidos no Programa de Visitação Pública e Educação Ambiental do Plano de Manejo do Parque Estadual da Ilha do Cardoso (São Paulo, 2001). As ações necessárias para o ordenamento foram divididas em 03 etapas: Planejamento Participativo; Monitoramento e Fiscalização; Comunicação.

As análises dos dados das oficinas foram realizadas utilizando-se da Teoria de Análise de Conteúdo (BARDIM, 1997), por meio dos recursos da associação de palavras e temas.

A capacidade de suporte da praia e demais propostas de ordenamento foram definidas com base no histórico de uso, identificado por meio da estatística de visitantes do PEIC, em estudos científicos realizados com o boto-cinza na região, na experiência de utilização pelos seus usuários, nas sugestões mais acordadas das oficinas e na análise e decisão do Conselho Consultivo do PEIC. Posteriormente, a capacidade de suporte e demais propostas de ordenamento poderão ser ajustadas de acordo com os resultados do trabalho de monitoramento de impactos e conclusão de estudos específicos.

A etapa de Planejamento Participativo compreendeu a fase de diagnóstico dos principais problemas resultantes do elevado número de visitantes, através da realização de oficinas junto aos segmentos envolvidos com a atividade, bem como levantar propostas para solução dos problemas. Todos os encaminhamentos das oficinas foram registrados e os participantes identificados em listas de presença. A dinâmica das oficinas participativas seguiu um roteiro de apresentação e discussão abrangendo:

1 - Contextualização: dados de visitação do Parque Estadual da Ilha do Cardoso nos últimos anos, demonstrando o grande aumento do número de visitantes e principais dispositivos legais que incidem sobre o território e sobre as atividades desenvolvidas;

2 - Identificação dos problemas: principais problemas ocasionados à Unidade de Conservação nos últimos anos e levantamento de novos problemas pelos participantes das oficinas;

3 - Propostas de soluções: levantamento de propostas e soluções para os problemas identificados.

\section{RESULTADOS}

$\mathrm{Na}$ etapa de Planejamento Participativo foram realizadas 08 oficinas com os segmentos e atores diretamente envolvidos com atividade de visitação na Praia do Itacuruçá/Pereirinha, entre os dias 11 de Setembro e 03 de Outubro de 2014. As oficinas foram: 2 com CT Uso Público (9 e 7 conselheiros respectivamente), 1 com Secretaria de Turismo de Cananéia (6 técnicos), 1 com funcionários do PEIC (14 funcionários da Fundação Florestal), 1 com prestadores de serviços do PEIC (9 vigias de empresa contratada), 1 com comunidade caiçara 
do Itacuruçá (17 moradores da comunidade) e 2 com barqueiros comerciais - escunas e voadeiras (53 representantes do transporte náutico).

Somados e identificados as pessoas nas listas de presença das oficinas resultou em aproximadamente 100 pessoas que contribuíram na construção da proposta de ordenamento desta praia.

A Tabela I indica os principais problemas e propostas de soluções originários da oficina e que integram a proposta de ordenamento da visitação da praia do Itacuruçá/Pereirinha.

Tabela I - Problemas e propostas de soluções identificados nas oficinas participativas.

\begin{tabular}{|c|c|}
\hline Problemas & Proposta de solução \\
\hline $\begin{array}{l}\text { Receptivos comunitários: Falta } \\
\text { de banheiros e deficiência no } \\
\text { atendimento devido ao grande } \\
\text { número de pessoas }\end{array}$ & $\begin{array}{l}\text { - Formalização de solicitação emergencial de autorização } \\
\text { para reformas de banheiros com tratamento sanitário junto } \\
\text { ao PEIC; } \\
\text { - Diminuição de número de pessoas na praia nos picos de } \\
\text { visitação por meio de controle. }\end{array}$ \\
\hline $\begin{array}{l}\text { Limite máximo de pessoas na } \\
\text { praia por dia }\end{array}$ & Máximo total de 1.000 pessoas por dia. \\
\hline Mecanismos de controle & $\begin{array}{l}\text { - Implantação de bilhete/passagem: cota definida por dia; } \\
\text { - Estabelecimento de número de viagens permitidas por } \\
\text { embarcações turísticas no dia; } \\
\text { - Credenciamento das embarcações que atuam com } \\
\text { transporte turístico comercial no PEIC; } \\
\text { - Estabelecimento de aviso quando atingido a capacidade } \\
\text { máxima de turistas na praia, exemplo: hasteamento de } \\
\text { bandeira. }\end{array}$ \\
\hline $\begin{array}{l}\text { Raia de embarque e } \\
\text { desembarque: deriva de barcos } \\
\text { e Jet-ski para a área da raia; } \\
\text { amarrações de embarcações } \\
\text { nos cabos; não permanência da } \\
\text { raia durante o período fora da } \\
\text { temporada de verão. }\end{array}$ & $\begin{array}{l}\text { - A comunidade propõe controlar a raia conforme a } \\
\text { demanda de turistas (instalar e desinstalar periodicamente); } \\
\text { - Delimitação para atracação na praia com distância } \\
\text { mínima de } 100 \text { metros da raia; } \\
\text { - Largura da raia em mar de } 100 \text { m e em praia de } 50 \\
\text { metros; } \\
\text { - Proibição de amarrar embarcações na raia da praia; } \\
\text { - Proibição do transito de jet sky; } \\
\text { - Limite de desaceleração na chegada e aceleração na saída } \\
\text { da raia deve ser diminuído. }\end{array}$ \\
\hline $\begin{array}{l}\text { Embarque e desembarque no } \\
\text { Rio Perequê: Condições de } \\
\text { mal tempo e maré podem } \\
\text { ocasionar perigo na praia. } \\
\text { Trânsito de embarcações no rio } \\
\text { pode ocasionar acidentes com } \\
\text { turistas }\end{array}$ & $\begin{array}{l}\text { - Autorização especial para embarque/desembarque no rio } \\
\text { mediante orientação de responsável do Parque na praia } \\
\text { (guarda-parque ou monitor) quando em condições de mal } \\
\text { tempo ou de dificuldades físicas; } \\
\text { - Delimitação de área permitida para banhistas; } \\
\text { - Embarcações no rio necessitam ter proprietário sempre } \\
\text { presente e ficar atracado por tempo limitado. }\end{array}$ \\
\hline
\end{tabular}




\begin{tabular}{|c|c|}
\hline $\begin{array}{l}\text { Deficiência na equipe para o } \\
\text { receptivo da praia: salva vidas, } \\
\text { limpeza de lixo, contagem de } \\
\text { embarcações, monitoria de } \\
\text { trilhas e fiscalização }\end{array}$ & $\begin{array}{l}\text { - Parcerias para viabilização da equipe com Prefeitura, } \\
\text { barqueiros e comunidade (associação de moradores) } \\
\text { - Fundação Florestal: disponibilizar Guardas Parque, vigias } \\
\text { terceirizados e monitores ambientais; } \\
\text { - Fiscalizações pelo Pelotão Náutico da Polícia Ambiental; } \\
\text { - Atuaçãa de fiscais da Prefeitura de Cananéia; } \\
\text { - Atualização do credenciamento dos monitores ambientais } \\
\text { autônomos e planejamento de escala. }\end{array}$ \\
\hline $\begin{array}{l}\text { Controle de acesso na sede do } \\
\text { Núcleo Perequê. }\end{array}$ & $\begin{array}{l}\text { - Sinalização de "limite para banhistas" na margem do rio } \\
\text { Perequê e de "acesso somente com monitor ambiental" a } \\
\text { partir da guarita da ponte; } \\
\text { - Acesso pelo píer somente com autorização de funcionário } \\
\text { do PEIC e com acompanhamento de monitor ambiental. }\end{array}$ \\
\hline $\begin{array}{l}\text { Quebra de galhos da vegetação } \\
\text { de restinga e aberturas de } \\
\text { novas trilhas }\end{array}$ & - Demarcação das trilhas com cordas e placas. \\
\hline Lixo deixado na praia & $\begin{array}{l}\text { - Concentrar lixeiras nos receptivos; } \\
\text { - Orientação aos visitantes por barqueiros e receptivo de } \\
\text { praia. Detalhar obrigação no Termo de Responsabilidade } \\
\text { do Credenciamento das Embarcações pelo PEIC; } \\
\text { - Placa de orientação na raia de desembarque; } \\
\text { - Cartazes de orientação em estruturas receptivas. }\end{array}$ \\
\hline Ocorrência de Churrasco & $\begin{array}{l}\text { - Orientação de proibição por parte dos barqueiros e } \\
\text { receptivo na praia. }\end{array}$ \\
\hline
\end{tabular}

Em todas as oficinas realizadas houve consenso pelos representantes dos segmentos, a necessidade de limitar urgentemente o número de visitantes na Praia do Itacuruçá/Pereirinha.

O Grupo de Trabalho sistematizou e analisou os dados de visitação e os problemas e soluções identificados nas oficinas. Posteriormente este material foi analisado e elaborada a proposta de ordenamento pela Câmara Temática de Uso Público do Conselho Consultivo do PEIC.

Em sua $177^{a}$ reunião o Conselho Consultivo analisou a proposta da Câmara Temática de Uso Público e aprovou emergencialmente a limitação de 1.000 (mil) visitantes por dia na Praia do Itacuruçá/Pereirinha e os demais encaminhamentos operacionais propostos de ordenamento da visitação.

Em 07/05/2005 a Fundação Florestal publicou a Portaria FF/DE n 220/2015 que limita emergencialmente a visitação pública na Praia do Itacuruçá/Pereirinha em 1.000 (mil) visitantes por dia e estabelece a proibição de esportes náuticos potenciais causadores de molestamento aos cetáceos (Jet-ski, esqui aquático, entre outros). As restrições impostas por esta portaria têm um prazo de 21 meses após sua publicação, de modo a serem realizados estudos técnicos para a análise da capacidade de suporte estabelecida.

A etapa de Monitoramento e Fiscalização consiste no estabelecimento do Plano de Ação, o qual prevê: 
- Mecanismos de monitoramento e controle de embarcações e de visitantes, propostos nas oficinas de planejamento;

- Credenciamento das embarcações de turismo náutico comercial pelo PEIC;

- Planejamento e direcionamento das ações de fiscalização para a Praia do Itacuruçá/Pereirinha, durante os dias de maior fluxo de visitantes.

A etapa de Comunicação consiste na fase de divulgação de informações do ordenamento emergencial da Praia do Pereirinha do Parque Estadual da Ilha do Cardoso, com campanhas de informação aos visitantes, proprietários de embarcações, divulgação em rádios e emissoras de TV locais e regionais e instalação de placas de orientação aos visitantes na praia.

\section{CONCLUSÕES}

A metodologia utilizada com a participação efetiva dos atores envolvidos no diagnóstico, planejamento e elaboração da proposta de ordenamento apresentou-se eficiente do ponto de vista ambiental pela redução significativa do número de visitantes na praia em dias de pico e pelas limitações quanto ao tráfego de embarcações ocasionando maior segurança para a população de botos-cinza e para banhistas.

A elaboração de propostas de ordenamento da visitação pública em atrativos de UCs que apresentem excesso de exploração, mesmo quando não existem estudos específicos de capacidade de suporte, devem ser elaborados com os segmentos envolvidos na exploração do atrativo levando-se em conta a diminuição da pressão e o monitoramento continuado.

Efetivada a implantação desta proposta, propõem-se a revisão da mesma baseada no monitoramento continuado de modo a adequar melhorias ambientais e sociais, atendendo aos princípios de turismo de base comunitária e de observação de cetáceos.

\section{REFERÊNCIAS BIBLIOGRÁFICAS}

BARDIN, L. Análise de Conteúdo, São Paulo: Edições 70, 1977.

BRASIL. Lei $\mathbf{n}^{\circ}$ 9.985, de 18 de julho de 2000. Institui o Sistema Nacional de Unidades de Conservação da Natureza e dá outras providências. Disponível em: <http://www.planalto.gov.br/ccivil_03/leis/19985.htm>. Acesso: 27/10/2014.

CAMPOLIM, M. B.; PARADA, I. L. S.; YAMAOKA, J. G. Gestão Participativa da Visitação Pública na comunidade do Marujá - Parque Estadual da Ilha do Cardoso. IF Sér. Reg., São Paulo, n. 33, p. 39-49, 2008.

CAMPOliM, M. B.; GARCIA, A.P.; MOTOLlA, T. R. L. Proposta de ordenamento das áreas de camping da comunidade da Prainha Branca, Guarujá (SP). Revista Brasileira de Ecoturismo, São Paulo, v. 6, n. 5, p. 836-849, nov. 2013/jan. 2014.

CANANÉIA. Lei 2.129 de 21 de dezembro de 2011. Regulamenta as atividades com fins comerciais de turismo, lazer e esporte náutico no município de Cananéia. Disponível em: 
<http://www.cananet.com.br/html/LEI-2129-2011_turismo_nautico.pdf $27 / 10 / 2014$.

FILLA, G. F. Monitoramento das interações entre o boto-cinza Sotalia guianensis e atividades de turismo no Complexo Estuarino-Lagunar de Cananéia, litoral sul do Estado de São Paulo, Tese, Universidade Federal do Paraná, Brasil. 2008.

FILLA, G. F. et al. Proposal of creation of "previous zoning with regulation of use in the Estuarine Complex of Cananéia" aiming the conservation of the estuarine dolphin, Sotalia guianensis (Cetacea, Delphinidae), Pan-American Journal of Aquatic Science. v. 3, n. 1, p.75-83, 2008.

FILLA, G. F.; MONTEIRO-FILHO, E. L. A. 'Monitoring Observation Tourism Schooners of Estuarine Dolphins (Sotalia guianensis) in the Estuarine Complex of Cananéia, southeast Brazil', Aquatic Conservation: Marine and Freshwater Ecosystems, v. 19, n. 7, p.772778, 2009.

FILLA, G. F.; MONTEIRO-FILHO, E. L. A. 'O desenvolvimento do turismo náutico e a sua ligação com a observação do boto-cinza (Sotalia guianensis) na região de Cananéia, litoral sul do Estado de São Paulo', Revista Turismo em Análise, v. 20, n. 2, p.282-301, 2009.

FILLA, G. F. et al. The economic evaluation of estuarine dolphin (Sotalia guianensis) watching tourism in the Cananéia region, south-eastern Brazil. Int. J. Green Economics, v. 6, n. 1, p. 95-116, 2012.

FUndAÇÃO Florestal. Portaria Normativa $\mathbf{n}^{\circ}$ 045, de 26 de setembro de 2007. Disponível em: <http://fflorestal.sp.gov.br/files/2014/01/PORTARIA-F.F.-N\%C2\%AA0452007.pdf $>$. Acesso: 18/05/2015.

GEISE, L. Estrutura social, comportamental e populacional de Sotalia sp. (Gray 1886) (Cetacea, Delphinidae) na região estuarino-lagunar de Cananéia, SP e na Baía de Guanabara, RJ. M.Sc. Tese. Universidade de São Paulo, São Paulo, Brasil. p.199. 1989.

GODOY, D. F.; ANDRIOLO, A.; FILLA, G. de F. The influence of environmental variables on estuarine dolphins (Sotalia guianensis) spatial distribution and habitat used in the Estuarine Lagunar Complex of Cananéia, southeastern Brazil. Ocean and Coastal Management, v.106, p.68-76, 2015.

MEDINA, M. M. Análisis de efectividad del manejo de áreas protegidas con participación social. Contexto y marco conceptual. Cali: Editorial WWF Colombia. p.64. 2005

MITRAUD, S. Manual de ecoturismo de base comunitária: ferramentas para um planejamento responsável. Brasília, DF: WWF-Brasil, p.164, 2004.

MOAES, H. M. T.; MIGNON, M. C. Caracterizando os Visitantes do Parque Estadual da Ilha do Cardoso (SP): subsídio para o planejamento de atividades turística-educacional em áreas de manguezal. Revista Brasileira de Ecoturismo, São Paulo, v.5, n.3, p.648-665, set/dez 2012. 
MONTEIRO FILHO, E. L. A. Comportamento de caça e repertório sonoro do golfinho Sotalia brasiliensis (Cetacea, Delphinidae) na região de Cananéia, Estado de São Paulo. Ph.D. Tese. Universidade Estadual de Campinas, São Paulo, Brasil. p. 99, 1991.

SANTOS, M. C. O. et al. The Triumph of the Commons: Working Towards the conservation of Guiana Dolphins (Sotalia Guianensis) in the Cananéia estury, BRAZIL. In: The Latin American Journal of Aquatic Mammals, 2010. v. 8, n.1 - 2. p. 187-190.

SANTOS, M. C. O. Uso de área e organização social do boto tucuxi marinho, Sotalia fluviatilis (Cetacea, Delphinidae), no estuário de Cananéia, SP. Ph.D. Tese. Universidade de São Paulo, São Paulo, Brasil. p.265, 2004.

SANTOS, M. C. O.; ROSSO, S. Ecological aspects of marine tucuxi dolphins (Sotalia guianensis) based on group size and composition in the Cananéia estuary, southeastern Brazil. Latin American Journal of Aquatic Mammals. June, 2007. Disponível em: <http://dx.doi.org/10.5597/lajam00110>. Acesso em: 21/05/2015.

SANTOS, M. C. O. Guiana dolphins (Sotalia guianensis) displaying beach hunting behavior in the Cananéia estuary, Brazil: social context and conservation issues. Brazilian Journal of Oceanography. 2010. Disponível em: <http://dx.doi.org/10.1590/S167987592010000200005>. Acesso em: 21/05/2015.

SÃO PAUlO. Secretaria do Meio Ambiente e Instituto Florestal. Plano de Manejo do Parque Estadual da Ilha do Cardoso - Fase 2. São Paulo, 2001. p. 174.

UNESCO. World Heritage Nomination - IUCN Technical Evaluation Atlhantic Forests (southeast). Brazil: UNESCO, p. 1-8, 1999.

UNESCO. World Network Of Biosphere Reserves - SC/EES. The MAB Program. p. 19, 2005. 